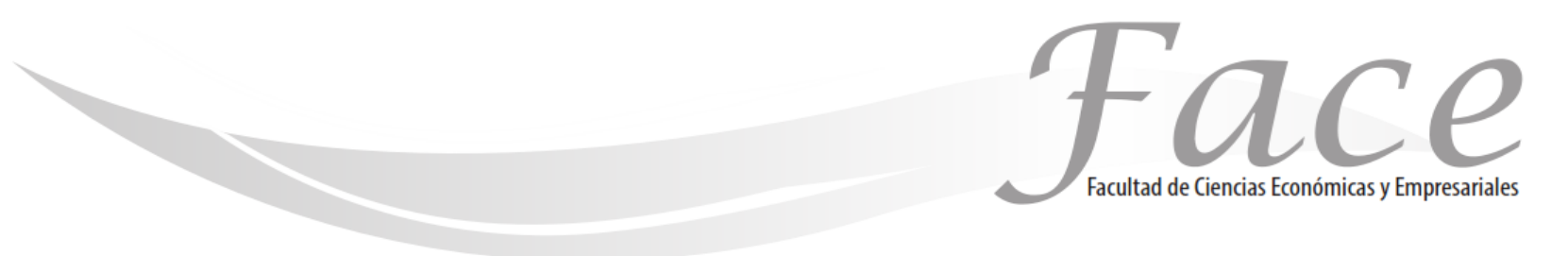

ISSN Impreso: 1794-9920 ISSN Electrónico: 2500-9338

Volumen $20-\mathrm{N}^{\circ} 2$

Año 2020

Págs. $85-94$

(c) (†) (9)

\title{
EVALUACIÓN DE RESULTADOS DEL SECTOR AGROEXPORTADOR DE MÉXICO ANTE LA PANDEMIA COVID-19 EN 2020
}

\author{
Adrián González Romo* \\ Enlace ORCID: http://orcid.org/0000-0003-1954-5185 \\ Mario Cruz Cruz ${ }^{* *}$ \\ Enlace ORCID: : http://orcid.org/0000-0003-1399-9223 \\ Yolanda Sánchez Torres* \\ Enlace ORCID: https://orcid.org/0000-0002-7372-6123
}

Fecha de Recepción: Septiembre 6 de 2020

Fecha de Aprobación: Diciembre 10 de 2020

\section{Resumen:}

Ante la pandemia del COVID 19 que azotó a la humanidad, el gobierno mexicano decidió detener todas las actividades económicas que limitaran la proliferación de los contagios. Muchas de ellas se vieron afectadas, sin embargo, las exportaciones de productos agropecuarias han mostrado un superávit en la balanza comercial. ¿Cómo se explica dicho incremento de esta actividad económica, cuándo se ha pronosticado una crisis generalizada de la actividad productiva?. El sector primario es un sector de primera necesidad que mantiene o incrementa la demanda de productos ante la misma inactividad de las personas que se refugian en sus domicilios y requieren alimentarse. El objetivo de esta investigación documental es mostrar la situación imperante del sector agroexportador ante la difícil situación provocada por la pandemia mundial en 2020.

Palabras clave: Balanza comercial, Sector agropecuario, Crisis económica

Palabras clave: ambiente, actitud ambiental, consumo responsable.

\footnotetext{
*Profesor Investigador del área académica de Comercio Exterior del Instituto de Ciencias Económico Administrativas (ICEA-UAEH), México. Contacto: adrian_gonzalez10100@uaeh.edu.mx

* * Investigador del área académica de Comercio Exterior del Instituto de Ciencias Económico Administrativas (ICEA-UAEH), México. Contacto: mario_cruz10096@uaeh.edu.mx

* * * Profesora Investigador del área académica de Comercio Exterior del Instituto de Ciencias Económico Administrativas (ICEA-UAEH), México. Contacto: yolanda_sanchez10097@uaeh.edu.mx
} 


\title{
EVALUATION OF RESULTS OF THE MEXICO AGRO-EXPORT SECTOR BEFORE THE COVID-19 PANDEMIC IN 2020
}

\begin{abstract}
:
Given the COVID 19 pandemic that hit humanity, the Mexican government decided to stop all economic activities that would limit the spread of infections. Many of those activities were affected, however, agricultural products exports have shown a surplus in the trade balance. How do you explain the increase in this economic activity, when a generalized crisis in productive activity has been predicted? Undoubtedly, the primary sector is a first necessity sector that maintains or increases the demand for products faced to the same people's inactivity who take refuge in their homes and have the need of feed themselves. The objective of this research document is to show the privileged position of the agroexport sector in the difficult situation caused by the global pandemic in 2020.
\end{abstract}

Keywords: Trade balance, Agricultural sector, Economic crisis

\section{VALIAÇÃO DOS RESULTADOS DO SETOR DE AGRO-EXPORTAÇÃO DO MÉXICO ANTES DA PANDÊMICA COVID-19 EM 2020}

\section{Resumo:}

Diante da pandemia COVID 19 que atingiu a humanidade, o governo mexicano decidiu interromper todas as atividades econômicas que limitariam a propagação de infecções. Muitas dessas atividades foram afetadas, no entanto, as exportações de produtos agrícolas têm apresentado superávit na balança comercial. Como o senhor explica o aumento desta atividade econômica, quando se prevê uma crise generalizada da atividade produtiva? Sem dúvida, o setor primário é um setor de primeira necessidade que mantém ou aumenta a demanda por produtos voltados para a inatividade das mesmas pessoas que se refugiam em suas casas e precisam se alimentar. $O$ objetivo deste documento de pesquisa é mostrar a posição privilegiada do setor agroexportador na difícil situação gerada pela pandemia global de 2020.

Palavras-chave: Balança comercial, Setor agrícola, Crise econômica. 


\section{INTRODUCCIÓN:}

El sector primario y fundamentalmente el sector agroexportador es un importante generador de divisas en la economía mexicana. El campo mexicano es considerado entre las 12 economías con mayor aporte a la producción agrícola en el mundo, por los empleos e ingresos que genera.

El año 2020 ha sido un año sumamente complicado por la situación provocada por la pandemia del COVID19 que ha azotado a toda la humanidad, sin una respuesta clara de contención ante el efecto expansivo que ha mostrado. La única salida inmediata fue paralizar la actividad social y económica para evitar contacto entre los individuos y ayudar a limitar los contagios, mientras se sigue trabajando en la búsqueda de una vacuna que evite se dé una mayor proliferación del virus y contenga la mortalidad que trae consigo.

Sin lugar a dudas el impacto en la economía no se ha dejado esperar, la demanda limitada en las actividades no esenciales, ha trastocando el ingreso de las familias, los empresarios resisten ante la contingencia y el estado ha evitado endeudar al país lanzando planes emergentes con financiamiento externo. Las decisiones provocan controversias, a favor y en contra, pero lo único claro es el efecto destructor que ha provocado la pandemia.

El estudio busca explicar la siguiente interrogante: ¿Cómo se explica que el sector agroexportador ha incrementado las exportaciones-ingresos en la economía mexicana, propiciando una balanza comercial superavitaria, al pronosticar una crisis generalizada de la actividad productiva? El objetivo de esta investigación, es señalar el papel tan relevante que juega el sector agropecuario ante la difícil situación de crisis provocada por la pandemia mundial en este año 2020, buscando con ello señalar la importancia de éste sector de la economía que ha mostrado un superávit de la balanza comercial entre las exportaciones e importaciones a favor de México., durante el primer semestre de 2020.
A pesar de esta situación tan critica que ha prevalecido en la economía, el sector agroalimentario mostró durante el primer semestre un crecimiento constante de las exportaciones, aun cuando también se observa de manera importante la dependencia en productos de primera necesidad que son importados, lo cual nos muestra la importancia de seguir impulsando dicho sector.

\section{MARCO TEÓRICO}

La economía frente a la crisis de la pandemia. La generalización de la pandemia del COVID-19 que ha estado azotando a la humanidad desde principios de este año 2020 no sólo ha afectado la salud de las personas, también ha desencadenado una recesión mundial profunda en la economía, que no se había visto en décadas, donde los estados nacionales tuvieron que decidir en controlar la pandemia y evitar más muertes, aun cuando afectará otros rubros. "Las prioridades políticas inmediatas son aliviar los costos humanos y atenuar las pérdidas económicas a corto plazo". Es un hecho que esta situación crítica no ha terminado, se tiene claro que la pandemia seguirá provocando contracciones en la gran mayoría de las economías de países desarrollados, de mercados emergentes y en desarrollo y causará un daño duradero a la productividad laboral y la producción potencial (Word Bank Group, 2020).

La situación se ha vuelto sumamente crítica y ha propiciado la toma de medidas drásticas que afectan la economía de cada país, ya que se han suspendido actividades económicas importantes como los servicios turísticos y con ello la industria aeronáutica, 0 sectores dinámicos que tuvieron que suspender actividades como la industria automotriz, que afectan el ingreso de las empresas y el empleo de los trabajadores.

Algunos países han utilizado el poder del estado para evitar crisis de contagios y mortandad, limitando y afectando industrias importantes, como es el caso de la aeronáutica en Estados Unidos, que prohibió la entrada a territorios estadounidense de vuelos procedentes de zonas infectadas por el COVID, entre ellos 26 países europeos y China en especial por ser el origen de la pandemia.

Ante ello la Asociación Internacional de Transporte Aéreo (IATA) señaló que las pérdidas para esta 
industria serían de alrededor de 113,000 millones de dólares, ya que emplean alrededor de 2.7 millones de personas. Durante 2019 los viajes entre Estados Unidos y la zona Schengen (26 países europeos) rondó los 200,000 vuelos y generó alrededor de 20,600 millones de dólares. Principalmente las rutas de Estados Unidos con Alemania, Francia e Italia, son las que están sufriendo las mayores consecuencias ya que generaron 10,400 millones de dólares en conjunto. Sólo en Estados Unidos esta industria emplea alrededor de 750,000 trabajadores (Méndez, 2020).

Por la crítica situación, el gobierno de Donald Trump acordó un rescate de 25,000 millones de dólares para evitar quiebras y despidos masivos con el compromiso de mantener el $90 \%$ de la plantilla laboral con sueldo íntegro. El Departamento del Tesoro anunció que American Airlines, Delta Airlines, United Airlines y Southwest y otras aerolíneas pequeñas aceptaron la ayuda del Gobierno (Monge, 2020). Sin embargo, el apoyo termina en septiembre y la pandemia continua, ante ello, seis uniones sindicales de los Estados Unidos pidieron al Congreso de los Estados Unidos un nuevo apoyo financiero de 32 mil millones de dólares para garantizar los salarios de los empleados de aerolíneas hasta el 31 de marzo de 2021, amenazando que iniciarían los despidos a partir de octubre (A21mx, 2020).

Las predicciones del Banco Mundial (8 de junio de 2020) sobre el panorama de la economía internacional, muestra que la reducción o caída del Producto Interno Bruto, sería de un 5.2\% para este año 2020. Se prevé que la actividad económica de las economías avanzadas se contraerá un poco más, siendo alrededor de $7 \%$, ante las distorsiones a la oferta y la demanda internas, limitaciones al comercio y estabilidad de las finanzas. Mientras que los mercados emergentes y las economías en desarrollo, la afectación será menor en $2.5 \%$, por tener una menor dependencia de la actividad comercial internacional. En ese mismo tenor, este organismo señaló que la economía de los Estados Unidos se reducirá en un $6,1 \%$ a raíz de las perturbaciones vinculadas con las medidas para controlar la pandemia y la inactividad económica de sus empresas.

El Word Bank Group (2020) señala que la situación que enfrenta México es crítica al señalar que en junio del 2020 la tasa de decrecimiento es del $-7.5 \%$, sin embargo, se espera que para la misma fecha del 2021, se logre tenga una recuperación gradual hasta llegar a una tasa de crecimiento del $3 \%$.

Todo un reto que hay que enfrentar para las economías nacionales, aclarando cuales son los medios y los fines. El cómo reactivar la economía compete al estado a través de su política fiscal, como un incentivador de las inversiones. Como jalar las inversiones del capital nacional y las inversiones extranjeras directas hacia la canalización de integración del Plan Nacional de Desarrollo, como eje articulador del desarrollo o cómo sacrificar, de alguna manera este propósito, por el bien de la sociedad.

El especialista en economía del Centro de Investigaciones económica de la UNAM, Arturo Huerta (2020), con una posición crítica afirmó recientemente, que el gobierno federal no ha hecho uso adecuado de la política fiscal, ya que sigue sin responder a los desafíos que la economía nacional está enfrentando. Huerta afirma que la necesidad de hacer uso de este instrumento es necesario ante la caída de exportaciones, donde "en abril la contracción anual fue de $-40.9 \%$; en mayo $-56.7 \%$; junio de $-12.8 \%$; en julio de -8.9", mientras que el gobierno solo aumentó el gasto público en $2.1 \%$ en el primer semestre y cerró con un superávit primario en el dicho semestre de 61,195 millones de pesos, por lo que la política fiscal en vez de contrarrestar la crisis, la profundiza".

Agricultura de exportación. Los productos agrícolas de exportación que se generan en el territorio mexicano, se relacionan directamente con las superficies que cuentan los sistemas de riego. De las 26 millones de hectáreas de tierras cultivables, existen 6.3 millones de hectáreas en la modalidad de riego, representando el $24 \%$ de la superficie de uso agrícola y $76 \%$ corresponde a tierras de temporal. Donde 3.4 millones de hectáreas (54\%) se ubican en 82 distritos de riego de alta irrigación, que se concentran principalmente en el noroeste del país, mientras que el restante $46 \%$ corresponden a 18,487 Unidades de Riego para el Desarrollo Rural (Vuelvas, 2016). La agricultura de riego utiliza $78 \%$ del agua aprovechable del país. Dentro de los sistemas más utilizados es el riego por gravedad en un $90 \%$, le sigue el riego presurizado. Dentro de este sistema de riego por gravedad predomina el riego con tuberías con compuertas en $57 \%$ de los casos, le sigue el riego de aspersión y microaspersión en $8 \%$ y sistemas de riego por goteo en $3 \%$ y $9 \%$ considerado como otro tipo. El 
$86.8 \%$ de las 630,313 unidades de producción utilizan agua blanca, $11.6 \%$ agua negra y el $1.1 \%$ utilizan agua negra no tratada. La utilización del agua para riego se considera que es desaprovechada, ya que el nivel de eficiencia considerada por la Comisión Nacional del Agua, es menor del 50\% (CNA, 2006).

Actividad agrícola que se encuentra ubicada en estados como Sinaloa, Sonora, Baja California Norte y Valle Lerma, Santiago-Pacífico que contribuyen con el $66 \%$ de la superficie agrícola sembrada. Mientras que el Pacífico Norte (Sinaloa y Nayarit) y el Noroeste (Sonora) contribuyen con $53 \%$ del valor de la producción (González, 2015).

\section{METODOLOGÍA}

La metodología empleada para el desarrollo de este trabajo de investigación está sustentado en el análisis de datos oficiales de la Balanza Comercial de Mercancías nacionales, elaboradas por las instituciones oficiales, como es el Banco de México, SAT, SE, INEGI, que se localizan en las páginas oficiales de dichas instituciones. El análisis está sustentado en estadística descriptiva, exposición en gráficas y cuadros de la información estadística generada directamente mes con mes por estas instituciones.

Los cuadros y gráficas son de elaboración propia con base a la información que presentan las instituciones oficiales del gobierno federal,

Se muestran los datos estadísticos más relevantes de este sector de la economía, sobre todo lo que compete a volumen de la producción e ingresos obtenidos, de tal manera permite poder analizar la importancia del sector agroexportador en la economía mexicana.

\section{RESULTADOS}

La producción del sector agropecuario está diversificada en el territorio nacional, y depende de las condiciones físico geográfico existentes de suelos, altitud, flora y fauna y niveles de precipitación. En algunos casos el agua es aprovechada con sistemas de irrigación modernos que ayudan a potencializar los rendimientos.

Sin lugar a dudas que hay que resaltar en estos momentos de inestabilidad económica, que las operaciones de la industria agroalimentaria en México tuvieron un repunte del $11.68 \%$ en el primer cuatrimestre de 2020. Esto se debe a que en general los productos perecederos no tuvieron afectaciones relevantes en las cadenas globales de valor. De hecho, este sector seguirá creciendo al mismo ritmo en los siguientes meses y será uno de los ámbitos económicos que menor afectación tendrá tras la crisis. Los productos que más elevaron sus números de exportación fueron el aguacate $(24.77 \% / 1,289$ millones de dólares), el tequila-mezcal (35.21\%/738 millones de dólares) y el jitomate $(13.09 \% / 1,019$ millones de dólares) (COMEXT, 2020).

Según datos del Servicio de Información Agroalimentaria y Pesquera (SIAP), el campo mexicano se ubica entre las 12 economías con mayor producción agrícola en el mundo, actividad que emplea a 5.5 millones de sus habitantes que generan 514,000 millones de pesos al año en productos agrícolas y se prevé que la producción de los granos de maíz, trigo, frijol y arroz, se incrementará en $8 \%$, respecto de 2019 , y pronostica que llegará a las 34 millones de toneladas (SAGARPA, 2020).

El aguacate ocupa el primer lugar en exportaciones, así lo señala el top ten de la Agricultural Marketing Service (2020) provenientes de Michoacán, le sigue la producción del limón cultivado en la costa del pacífico, mango (principalmente de Chiapas), chile, tomates diversos (provenientes de Sinaloa), pepinos, productos tropicales, pimiento morrón y sandía (del Noroeste de México), cultivados la mayoría en tierras de riego, tanto en propiedades privadas como ejidales (cuadro 1). 
Cuadro 1. Top ten de las exportaciones agrícolas de México (toneladas)

\begin{tabular}{|l|c|c|}
\hline \multicolumn{1}{|c|}{ COMMODITY } & $\begin{array}{c}\text { 3er qtr } \\
2019\end{array}$ & Rank \\
\hline Avocados & 211 & 1 \\
\hline Limes & 166 & 2 \\
\hline Mangoes & 147 & 3 \\
\hline Peppers, Other & 141 & 4 \\
\hline Tomatoes, plum type & 139 & 5 \\
\hline Tomatoes & 117 & 6 \\
\hline Cucumbers & 95 & 7 \\
\hline Misc tropical & 84 & 8 \\
\hline Peppers, bell type & 49 & 9 \\
\hline Watermelons & 47 & 10 \\
\hline
\end{tabular}

La figura 1 nos señala la importancia del flujo comercial del sector agroindustrial, agrícola y pesquero, que muestra una balanza comercial superavitaria, donde se observa la importancia de la contribución de los productos agropecuarios por encima de los productos agroindustriales en las exportaciones, mientras que en las importaciones es lo contario se importan más productos agroindustriales que los productos agropecuarios.

Figura 1. Balanza del flujo comercial del sector agropecuario y agroindustrial durante el primer semestre de 2020 (miles de dólares)

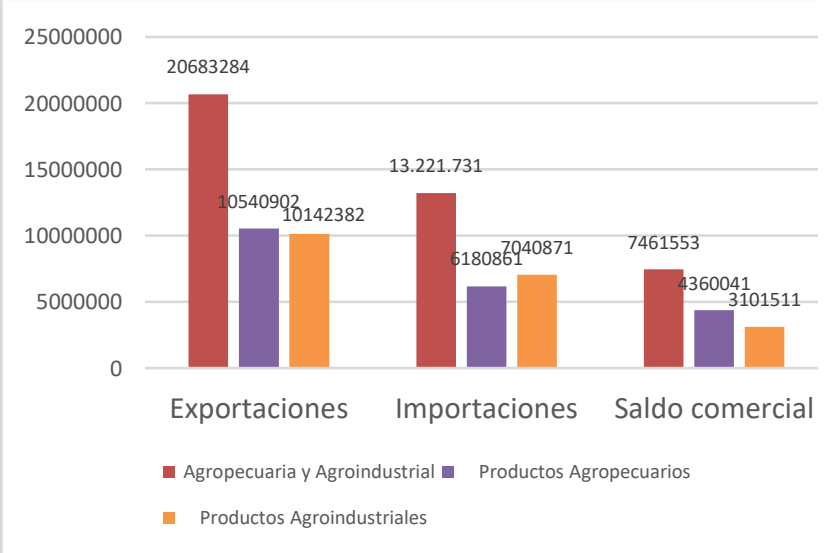

Fuente: Elaboración propia con base a datos del Banco de México, SAT, SE, INEGI. Balanza Comercial de Mercancías de México. SNIEG. Información de Interés Nacional, 2020

El saldo de la balanza comercial del sector Agropecuaria y Agroindustrial fue positivo durante el primer semestre del año 2020. El sector Agropecuaria incluye los productos agrícolas, apícolas, ganadero y pesquero, mientras que el sector agroindustrial está compuesto por a). Alimentos, bebidas y tabacos, b). Productos químicos, c). Productos textiles y del cuero $\mathrm{y}$ d). Otras manufacturas. En la figura 1 se muestra el promedio semestral, mientras que la figura 2 , se muestra el comportamiento mensual durante el mismo periodo.

Figura 2. Saldo de la balanza comercial Agropecuaria y Agroindustrial, por meses, 2020 (miles de dólares)

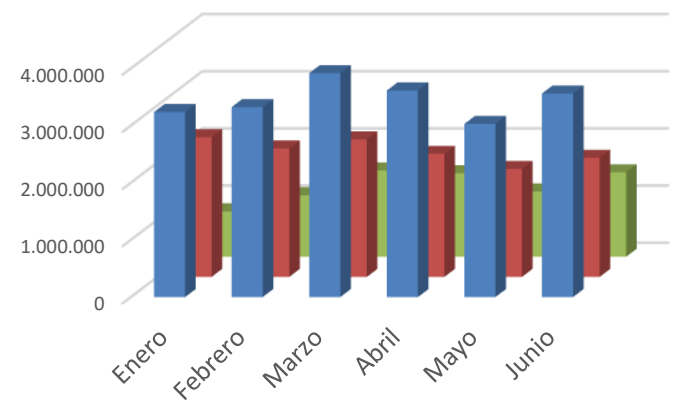

- Exportaciones Importaciones Saldo Comercial

Fuente: Elaboración propia con base a datos del Banco de México, SAT, SE, INEGI. Balanza Comercial de Mercancías de México. SNIEG. Información de Interés Nacional, 2020

La balanza comercial del sector agropecuario y agroindustrial fue superavitaria, con un incremento importante de un ingreso al ser de 1,141,704 (en miles de dólares) en enero y pasar en el mes de junio a $1,476,775$ (miles de dólares), es decir, se muestra un crecimiento del $86 \%$ en este periodo, principalmente en marzo con el $90 \%$ (figura 2).

\section{La contribución de los productos agrícolas en la exportación de productos agropecuarios}

El superávit de productos agrícolas durante el primer semestre del 2020, muestra la relevante contribución de las exportaciones de este sector a la economía, principalmente en lo que se refiere a las contribuciones de ingresos, al pasar de enero al mes de junio del 2020 de 710 MDD a 747 MDD, es decir un incremento de 5.18. El incremento más importante se muestra de enero a marzo, al ser de alrededor del $35 \%$ en dicha 
balanza comercial (figura 3) (BANCO DE MÉXICO, 2020).

Figura 3. Balanza comercial del sector agropecuario primer semestre 2020 (miles de dólares)

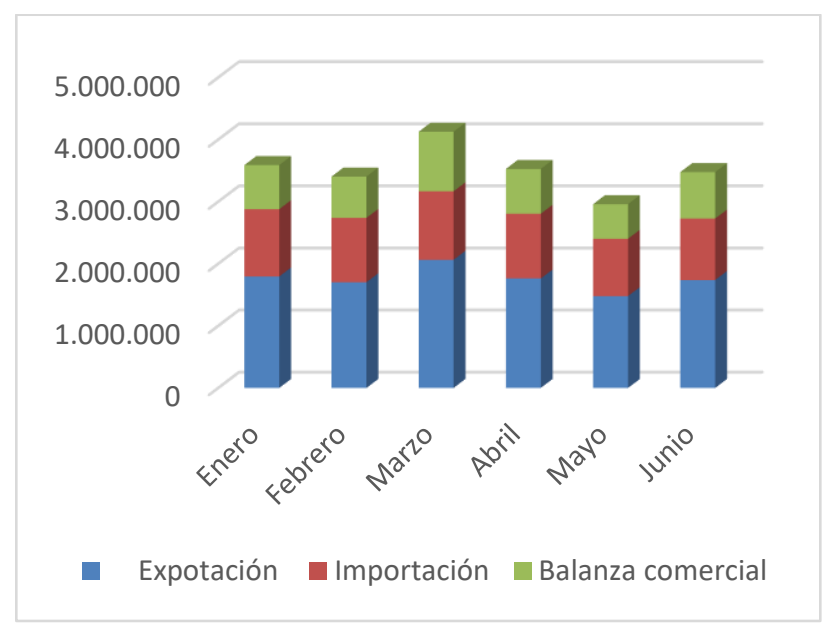

Fuente: Elaboración propia con base a datos del Banco de México, SAT, SE, INEGI. Balanza Comercial de Mercancías de México. SNIEG. Información de Interés Nacional, 2020.

Existe un total de 26 de productos agropecuarios con los que México está contribuyendo al mercado norteamericano y que se mantienen a pesar de esta situación de pandemia, suscitada a nivel mundial y que en muchos lugares los mercados colapsaron.

Sin lugar a dudas la exportación de aguacate, jitomate, uvas-pasas y otras legumbres y hortalizas frescas, son los productos que contribuyen de mejor forma a las exportaciones, representando el $45 \%$ en promedio en los últimos tres meses, sin embargo, los otros productos exportados juegan un papel importante en la balanza comercial (figura 4).
Figura 4. Los 12 principales productos agropecuarios de exportación de abril a junio 2020 (miles de dólares)

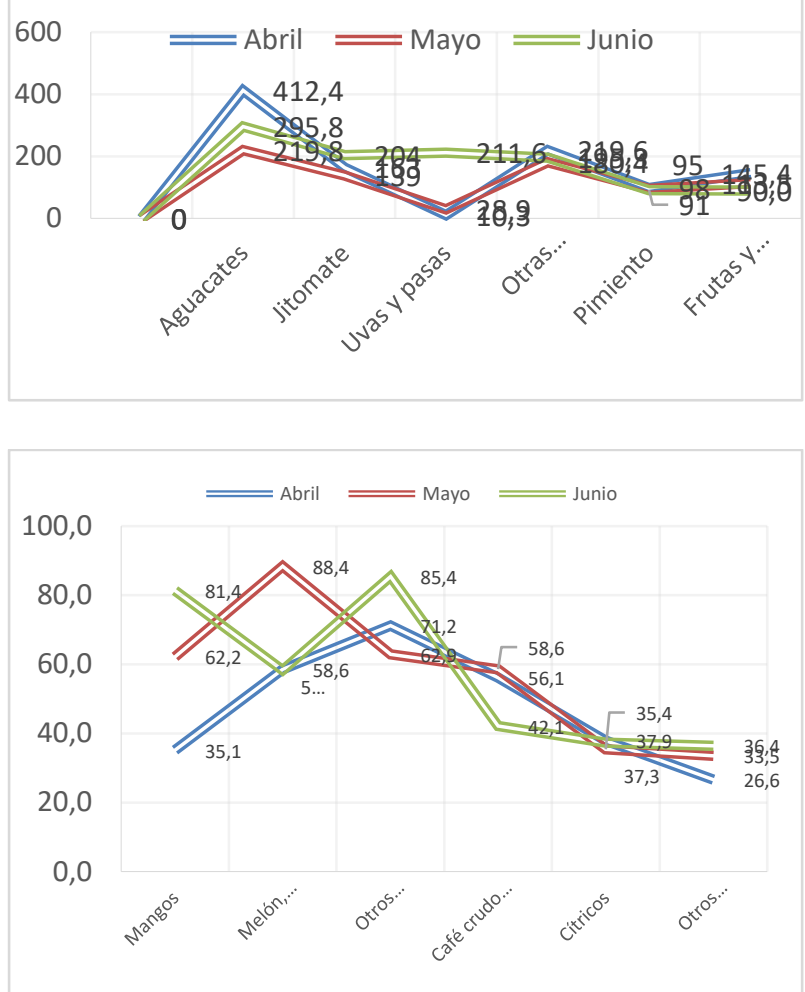

Fuente: Elaboración propia con base a datos del Banco de México, SAT, SE, INEGI. Balanza Comercial de Mercancías de México. SNIEG. Información de Interés Nacional, 2020.

A pesar de que México mantiene una balanza superavitaria hay productos de primera necesidad que siguen importándose y que tienen balanza deficitaria. Durante este período de la pandemia se muestra un crecimiento importante de los diferentes productos importados. 
Cuadro 2. Principales productos agropecuarios importados por México, 2020

(Miles de Dólares)

\begin{tabular}{|c|c|c|c|}
\hline & Abr & May & Jun \\
\hline - Maíz & 279,214 & 248,025 & 244,947 \\
\hline $\begin{array}{l}\text { - Semilla de } \\
\text { soya }\end{array}$ & 176,348 & 196,818 & 168,367 \\
\hline - Trigo & 127,114 & 63,794 & 80,863 \\
\hline $\begin{array}{l}\text { - Leche y sus } \\
\text { derivados }\end{array}$ & 75,538 & 71,907 & 87,231 \\
\hline $\begin{array}{l}\text { - Semillas de } \\
\text { nabo o colza }\end{array}$ & 56,976 & 23,134 & 72,065 \\
\hline $\begin{array}{l}\text { - Pescados, } \\
\text { crustáceos y } \\
\text { moluscos }\end{array}$ & 39,654 & 24,988 & 24,354 \\
\hline - Arroz & 34,875 & 41,430 & 43,537 \\
\hline $\begin{array}{l}\text { - Semillas para } \\
\text { siembra }\end{array}$ & 29,884 & 45,225 & 43,192 \\
\hline Suma & 819,603 & 715,321 & 764,556 \\
\hline
\end{tabular}

Fuente: Elaboración propia con base a datos del Banco de México, SAT, SE, INEGI. Balanza Comercial de Mercancías de México. SNIEG. Información de Interés Nacional, 2020

En total son 22 los principales productos importados, pero de estos son 8 los que más contribuyen, correspondiendo al $77 \%$ de los egresos por productos importados. Para el mes de junio 2020, el maíz fue el producto importado más importantes con una contribución del $25 \%$, semillas de soya con un aporte de $17 \%$, los otros 6 productos se pueden observar en el cuadro 2, con un porcentaje de menor relevancia.

A nivel del total de los productos importados observamos una caída del $-5 \%$ de abril a junio de este año. 10 productos de los 22 contrajeron sus importaciones, la principal reducción se dio en Sorgo (76\%), pimienta, chiles o pimientos secos $(61 \%)$, pescados, crustáceos y moluscos $(39 \%)$, trigo $(-36 \%)$, huevo $(-25 \%)$, mientras los que se incrementaron en forma importante fue el algodón (200\%), el rubro de otros cereales (93\%), semillas para siembra $(44.5 \%)$, manzanas, peras y membrillos (36\%).
Aun cuando el maíz redujo las importaciones, al disminuir en $12 \%$, sigue siendo el principal producto de importación al contribuir con $25 \%$ del total de las importaciones mexicanas del mercado norteamericano.

\section{CONCLUSIONES}

La situación actual de la economía mexicana ente la pandemia se puede resumir en dos aspectos:

1). Que lo que explica el superávit de la balanza comercial es que las exportaciones del sector agropecuario y agroindustrial, son productos básicos de primera necesidad y que a pesar de cualquier contingencia no se limita su demanda y se requieren en la mesa de los consumidores, aun cuando estén en resguardo domiciliario.

2). Mientras que los productos de bienes de consumo de capital o duradero sufren las consecuencias de la disminución de los ingresos o la paralización de la producción ante la limitada demanda.

Este tipo de bienes el gobierno federal los consideró no esenciales de tal manera limitó su producción a sólo los esenciales. Sin embargo, levantó esta prohibición en el mes de junio a otro tipo de industrias, relevantes a la actividad económica, es decir se reclasificaron como esenciales, y comenzaron a realizar su actividad bajo medidas estrictas y evitando que los trabajadores mantuvieran contacto directo, como el caso de la industria automotriz y la industria de servicios, hotelera y restaurantera (con un cupo limitado).

La contribución del sector agropecuario a la economía mexicana a través de sus exportaciones es un indicador relevante que nos muestra la atención que se debe dar a este sector. Por un lado, la diversidad de productos que se exportan y hacen que la balanza comercial sea superavitaria muestra la riqueza de productos que generamos en el sector agroexportador y la necesidad que tiene un país tan importante en demanda como es Estados Unidos.

Así mismo se muestra la dependencia de productos tan importantes como es el maíz amarillo, la soya, el trigo y el arroz tanto para el consumo directo, pero principalmente para la industria de transformación. Dicha situación nos está indicando la atención para la 
búsqueda de la autosuficiencia alimentaria, como un mecanismo de soberanía frente a los mercados internacionales.

La pandemia afectó a todos los sectores de la actividad económica que se consideran ser bienes de consumo duradero, pero el sector agropecuario no dejó de mandar sus productos al mercado norteamericano, lo cual muestra la fortaleza que tiene frente a los demás sectores de la economía mexicana.

Por ello es importante señalar que la política empleada en el sector agropecuario debe de poner atención a los productores del campo, ofreciendo mejores oportunidades, créditos, acceso a la maquinaria e insumos para reactivar este sector que ha sido olvidado durante muchos años y de esta manera permita incorporar nuevos actores en los mercados de exportación.

\section{REFERENCIAS:}

BANCOMEXT (2020). Las secuelas económicas de la pandemia. Nueva época $\mathrm{N}^{\circ} 23$, JulioDiciembre, México. Versión en PDF en http://www.revistacomercioexterior.com/revist as/23/1598029586312.pdf

Banco de México. Sistema de Información Económica (2020). Balanza de Productos Agropecuarios y Agroindustriales en línea en https://www.banxico.org.mx/Sielnternet/cons ultarDirectoriolnternetAction.do?accion=cons ultarCuadro\&idCuadro $=$ CE123\&sector $=1 \& l o c$ ale $=$ es. Consultado 09/09/2020.

Banco Mundial (8 de junio de 2020). La COVID-19 (coronavirus) hunde a la economía mundial en la peor recesión desde la Segunda Guerra Mundial, en línea en https://www.bancomundial.org/es/news/press -release/2020/06/08/covid-19-to-plungeglobal-economy-into-worst-recession-sinceworld-war-ii. Consultado 01/09/2020.
Méndez, L. (13/03/2020) Medidas por Covid-19 ponen en peligro a las aerolíneas, según la IATA en línea en https://www.france24.com/es/20200313economia-coronavirus-aerolineas-iata. Consultado 03/09/2020.

Monge, Y. (14/04/2020). Trump acuerda un rescate con las aerolíneas de Estados Unidos. El Páis, en línea en https://elpais.com/economia/2020-0414/trump-acuerda-un-rescate-con-lasaerolineas-de-estados-unidos.html, Washington, EUA, Consultado 03/09/2020.

A21mx (2020). Piden sindicatos de EU otro rescate de 32 mil mdd, en línea en https://a21.com.mx/index.php/aerolineas/202 0/06/26/piden-sindicatos-de-eu-otro-rescatede-32-mil-mdd. Consultado 03/09/2020.

CNA (2006). El agua en México. en http://www.conagua.gob.mx/CONAGUA07/P ublicaciones/Publicaciones/EL-AGUA-ENMEXICO.pdf

González, A., Hernández, P. (2015). El sector agropecuario mexicano frente al TLCAN: un balance de su contribución en Hernández, T. J., González, A., Estrada, R. y Moreno, H. Cambios e innovación una visión estratégica para el desarrollo. E-BOOK, UATX-México, 1755-1773.

Huerta, A. (01/09/2020). Continúa la irresponsabilidad de la política económica para superar la crisis en línea en https://julioastillero.com/continuala-irresponsabilidad-de-la- politicaeconomica-para-superar-la-crisis-autorarturo-huerta-gonzalez/?fbclid= IwAR1M0vFSQFV8vxRFevS1S8bKCHA9dU wkvyrcn7GP2z8IZ3t43LEvm_Vz200. Consultado el 01/09/2020.

SAGARPA (2020). Producción para el Bienestar transforma el campo, en https://www.gob.mx/agricultura/articulos/prod uccion-para-el-bienestar-transforma-elcampo?idiom=es. Consultado 01/09/2020. 
USDA, Agricultural Marketing Service (AMS) (17-032020). Las10 principales exportaciones agrícolas de México por camión a EU. Opportimes en línea https://www.opportimes.com/las-10principales-exportaciones-agricolas-demexico-por-camion-a-eu/. Consultado 03/09/2020.

Vuelvas, M.A. (2016). Las unidades de riego para el Desarrollo Rural. CEDRSSA-Palacio Legislativo de San Lázaro. http://www.cedrssa.gob.mx/files/b/8/82Unida des_riego_desarrollo_rural.pdf. Ciudad de México.

Word Bank Group (2020). Global Economic Prospects June 2020. International Bank for Reconstruction and Development / The World Bank. Washington, DC. Documento en pdf. En línea en https://www.worldbank.org/en/publication/glo bal-economic-prospects. Consultado 01/09/2020. 